\title{
Genetics of oviposition success of a thelytokous fairyfly parasitoid, Anagrus delicatus
}

\author{
JAMES T. CRONIN* \& DONALD R. STRONG \\ Bodega Marine Laboratory, University of California, P.O. Box 247, Bodega Bay, CA 94923, USA
}

\begin{abstract}
The foraging behaviour of the salt-marsh parasitoid, Anagrus delicatus (Hymenoptera: Mymaridae), is distinguished by few eggs laid per patch of hosts and frequent dispersal among patches. We investigated the within-population genetic variability in six quantitative traits associated with this unusual behaviour: fecundity (lifetime number of eggs), time on a patch, number of ovipositions per patch, oviposition rate, ovipositor length and tibia length (a measure of body size). Forty-one wasp isolines were initiated from single parthenogenetic females from three isolated salt marshes, and were maintained for up to eight generations in the greenhouse. We estimated the genetic variance and broad-sense heritability $\left(h^{2}\right)$ of these traits and tested trait means for differences among isolines (genetic variation) and sites (geographical variation). We found significant genetic variability among isolines for all traits except oviposition rate. The behavioural and morphological traits had similar levels of genetic variance, indicating that the evolvability (ability to respond to selection) of the traits is similarly high. However, the behavioural traits had higher residual variances, resulting in lower heritabilities. Only two traits had significant heritabilities. Fecundity, which is probably a good proxy for fitness, ceteris paribus, varied from on average 26 to 40 eggs per isoline and had the highest $h^{2}, 0.47 \pm 0.16$ (mean $\pm \mathrm{SE}$ ). Ovipositor length had an $h^{2}$ of $0.36 \pm 0.17$. These results suggest that the traits comprising the foraging strategy of $A$. delicatus should be amenable to selection (e.g. isolines could be selected that lay more eggs per host patch and consequently visit fewer patches). Genetic correlations among traits were numerous and positive. One important prediction from these data is that selection for larger wasps will result in large offspring with greater egg loads and higher oviposition rates. Wasps with this combination of attributes are likely to be more efficient natural enemies for use in biological control. In addition, there was no significant divergence (genetic or otherwise) in wasp morphology or behaviour among the three sites, even though they were separated by $8 \mathrm{~km}$ or more.
\end{abstract}

Keywords: Anagrus delicatus, fecundity, genetic variability, oviposition behaviour, parasitoid quantitative genetics, Prokelisia marginata.

\section{Introduction}

Insect parasitoids have long served as model organisms for the study of animal foraging behaviour and its evolution (for reviews see Bouletreau, 1986; Stephens \& Krebs, 1986; Mangel \& Clark, 1988; Godfray, 1993). These studies have identified numerous behavioural, morphological and physiological traits that affect an individual parasitoid's foraging success (aggregative search, egg load, time on a patch, ovi-

\footnotetext{
*Correspondence: Department of Biology, Bucknell University, Lewisbury, PA 17837, U.S.A.
}

positor length, etc.). The evolution of a few of these traits has been modelled: for example, sex ratio (Hamilton, 1967; Taylor \& Bulmer, 1980; Nunney \& Luck, 1988), clutch size (Parker \& Courtney, 1984; Godfray, 1987; Charnov \& Skinner, 1988; Godfray \& Ives, 1988), and adaptive superparasitism (Mangel, 1992; Visser et al., 1992). Although models have either implicitly (e.g. ESS models) or explicitly (e.g. single gene or quantiative genetic models) assumed genetic variance in these traits, there is actually little known of their genetic basis in parasitoids (but see Chassain \& Bouletreau, 1987, 1991; Carton et al., 1989; Wajnberg et al., 1989; Orzack \& Parker, 1990; 
Prevost \& Lewis, 1990; Carton \& Nappi, 1991; Mollena, 1991; Sequiera \& Mackauer, 1992a,b; Wajnberg, 1993; Onzack \& Gladstone, 1994).

Over the past 12 years we have amassed considerable information regarding the biology, foraging behaviour and population dynamics of the parasitoid Anagrus delicatus Dozier (Hymenoptera: Mymaridae). We have found that the foraging behaviour of this wasp is unusual with respect to many parasitoids because the adult female lays only a small fraction of her mature eggs in each patch of hosts, and then disperses (Cronin \& Strong, 1993a). Frequent dispersal, despite abundant hosts per patch, results in parasitoid eggs being distributed among many host patches. One hypothesis to explain this behaviour is risk spreading (Strong, 1988; Cronin \& Strong, 1993a). Other hypotheses are that the inability to discriminate previously parasitized hosts (Cronin \& Strong, 1993b), or subtle variations in host quality, could lead to high patch-leaving rates (Rosenheim \& Mangel, 1994; Bouskila et al., 1995).

Time spent, number of ovipositions and the rate of oviposition per patch are the behavioural traits that best characterize the unusual foraging strategy (risk-spreading or otherwise) of A. delicatus. Recently, we (Cronin \& Strong, 1993a) described substantial phenotypic variability in each of these traits. In this paper, we examine the genetic variability in these behavioural traits in three parthenogenetic populations of $A$. delicatus. In addition, we estimate the genetic variability in fecundity (lifetime number of eggs), body size and ovipositor length, three traits that may contribute to oviposition success. Finally, we determine the genetic correlations among traits and whether trait means vary among sites (e.g. geographical differentiation). These quantitative data are used to provide information on the potential for evolution and to provide the framework for the development of a genetic-based model to predict the evolution and selective advantage of the unusual oviposition strategy of $A$. delicatus.

\section{Methods}

\section{Biology and life history of Anagrus delicatus}

Anagrus delicatus is a minute $(\approx 0.7 \mathrm{~mm}$ total body length) solitary parasitoid that attacks the eggs of two conspecific planthoppers, Prokelisia dolus Wilson and $P$. marginata (Van Duzee) (Homoptera: Delphacidae) (Cronin \& Strong, 1990). These planthoppers are abundant herbivores of intertidal marshes along the Atlantic, Gulf and Pacific Coasts of the United States and Mexico, where they feed on and lay eggs in the leaves of cord grasses in the genus Spartina (Stiling \& Strong, 1982; Denno et al., 1987; Roderick, 1987). In northern California only $P$. marginata is present, feeding on both native $S$. foliosa and recently introduced (ca. 1975; Spicher \& Josselyn, 1985) S. alterniflora.

Anagrus delicatus has both arrhenotokous (females produced from fertilized eggs, males from unfertilized eggs) and thelytokous (females produced from unfertilized eggs, males only rarely appearing) populations. In Florida, at least a large fraction of females (if not all) are arrhenotokous (Cronin \& Strong, 1990). In California, from San Francisco Bay northward, we have found all wasps to be thelytokous; females comprised up to 99.5 per cent of the offspring. In $A$. delicatus, thelytoky appears to be genetically based, and not induced by sex-ratio distorting bacteria (J. T. Cronin \& D. R. Strong, unpublished data), as has been found in other parasitic wasps (e.g. Werren et al., 1986; Stouthamer \& Luck, 1993; Stouthamer \& Werren, 1993). The origin and age of the thelytokous populations and the cytological mechanism of reproduction in $A$. delicatus are not known. However, provided the condition has persisted for several generations, even an endomeiotic system should produce mothers and daughters that are virtually genetically identical (Charlesworth \& Charlesworth, 1987).

Arrhenotokous and thelytokous populations of $A$. delicatus are otherwise indistinguishable with respect to their morphology, behaviour and ecology (J. T. Cronin \& D. R. Strong, unpublished data). Adult wasps live an average of 1-2 days and eclose with an average ( $\pm \mathrm{SE}$ ) of $33 \pm 0.6$ eggs (range 21-45) in their reproductive tracts (Cronin \& Strong, 1990, 1993a). These eggs are mature and functional. No other eggs develop during the wasp's short lifespan, and wasps do not reabsorb existing eggs (i.e. wasps are pro-ovigenic). Females lay an average of six eggs per patch of hosts, then move to another patch. This low oviposition rate per patch is independent of host and parasitoid density and is not a consequence of egg or time limitations. While females have a large fraction of their eggs remaining, they abandon patches that still have many available hosts.

\section{Rearing procedure}

We used $S$. alterniflora as the host plant for all laboratory experiments. Single culms were planted in $10 \times 10 \mathrm{~cm}$ pots and grown in a greenhouse to a size of $40-80 \mathrm{~cm}$ in height. Culms bore c. 4-6 green leaves.

Hosts for the parasitoids were $P$. marginata eggs. Adults of this planthopper were collected with a 
sweepnet from $S$. alterniflora in a restored marsh in the Hayward Regional Shoreline, Alameda Co., CA, and returned to the laboratory. Sixteen females and four males were placed into a clip cage. The cage was constructed of a $40 \mathrm{~mm}$ length of $18 \mathrm{~mm}$ diameter acetate tubing that was inserted over a single cord grass leaf. The tubing was positioned at the base of the leaf and capped at either end, leaving the upper leaf surface exposed (Cronin \& Strong, 1990). The planthoppers were placed into the cages for a $48 \mathrm{~h}$ period to feed upon and oviposit into the leaf sections. This produced patches of host eggs of uniform age and size. An average of 154 hosts \pm 5 (SE) $(n=378)$ was obtained, which is in the upper quartile of host densities found in nature (Stiling \& Strong, 1982; Strong, 1989).

Anagrus delicatus was collected from three marshes in the San Francisco Bay: the Hayward Regional Shoreline (HS); Coyote Creek Slough, San Francisco Bay National Wildlife Refuge, Alameda Co. (CC); and the San Francisco airport (Samtrans bus terminal), San Mateo Co. (SF). HS is $8 \mathrm{~km}$ north of CC on the east side of San Francisco Bay and $21 \mathrm{~km}$ across the bay from SF; CC is $24 \mathrm{~km}$ south-east of SF, across the bay. All three marshes were a mixture of $S$. foliosa and $S$. alterniflora, and represent the only sites in the Bay Area that support both host plants (J. T. Cronin and D. R. Strong, unpublished data).

Spartina alterniflora leaves, infested with planthopper eggs and developing parasitoids, were collected from each site during the first two weeks of March, 1992. One leaf from each of 100 plants was collected from as wide a sampling area as possible in each site: $c .0 .25 \mathrm{~km}^{2}$ at $\mathrm{SF}$ and $\mathrm{CC}$, and $0.5 \mathrm{~km}^{2}$ at $\mathrm{HY}$. Leaves were returned to the laboratory, and pupal female wasps were excised from between the leaf veins and placed in petri plates containing a moistened filter paper disc. In an attempt to sample the population broadly, only one pupa was taken from each leaf and plant. Petri plates were checked daily for adult eclosion. Each emergent female was released alone into a clip cage surrounding a patch of host eggs, and was left to oviposit for 2 days (equivalent to the lifespan of an adult parasitoid). These unmated adults comprised the foundresses of the wasp isolines and their offspring, the $F_{1}$ generation. After the 2-day oviposition period, plants bearing the host patches were placed in the greenhouse for development of the $F_{1}$ generation. Clip cages were left on the leaves to exclude other parasitoids from host patches. Approximately 24 days were required for the parasitoids to complete development in the greenhouse. Twenty-one days after attack, leaves with host patches were cut, brought back to the laboratory, and placed in separate bowls with lids. All bowls were checked daily for $F_{1}$ adults. Upon emergence, wasps were placed individually in clip cages and left to parasitize hosts for 2 days. All offspring from the foundresses were used. Following a 21-day incubation period in the greenhouse, leaves from each isoline were consolidated into as few bowls as possible; no more than six leaves were placed in a single bowl. These next generation, $\mathrm{F}_{2}$, offspring (a maximum of 25 individuals) were used to perpetuate the isolines. This procedure was repeated for up to eight generations, ending in midNovember, 1992 when adult planthoppers could no longer be found in sufficient numbers in the field to continue the isolines. For each wasp isoline and generation, we recorded the number of wasps comprising the isoline and its sex ratio. Twenty-six isolines were initiated for the HS site, 17 for SF and 20 for $\mathrm{CC}$.

\section{Genetic variation in morphology}

During the second and third generations, five newlyeclosed adult wasps (which had laid no eggs) were chosen haphazardly from each isoline for measurement of hind tibia length, ovipositor length and egg number. Wasps were dissected under a compound dissecting microscope at $50 \times$ magnification and their eggs counted. The remains of each wasp were then transferred on a glass slide to a compound light microscope, where the ovipositor and both hind tibiae were measured with an ocular micrometer at $200 \times$. We averaged the pair of hind tibia lengths from each wasp. Because $A$. delicatus is pro-ovigenic, egg number represents the wasp's maximum potential lifetime fitness (Cronin \& Strong, 1993a). Tibia and ovipositor length were measured because they are correlated with total body length (tibia: $r^{2}=0.39$, $P<0.001$; ovipositor: $\left.r^{2}=0.36, P<0.001\right)$. Ovipositor length may have additional relevance to wasp fitness because access to hosts is often restricted to wasps with long ovipositors (e.g. Ball \& Dahlsten, 1973; Weis et al., 1985). Between the sixth and eighth generations, the three morphological traits were measured from an additional five wasps per isoline.

\section{Genetic variation in oviposition behaviour}

During the third to seventh generations, a total of 10 wasps were randomly chosen from each isoline and used to study $A$. delicatus oviposition behaviour. Behavioural trials were conducted between 0900 and $1600 \mathrm{~h}$. Cord grass plants, bearing one host patch each, were positioned on a laboratory bench with 
artificial light provided overhead by two tungsten lamps. A newly emerged wasp $(<8 \mathrm{~h}$ old $)$ was released on to each unenclosed patch of hosts, and at $5 \mathrm{~min}$ intervals the patch was examined for the presence or absence of the wasp. Wasps remained for long periods on single host patches, and a trial was continued until the wasp left the leaf bearing the patch, either by flying or walking. After dispersal from the leaf, the plant was placed in the greenhouse for 5 days and then the patch was dissected to determine host density and number of parasitized hosts. Parasitized hosts could be distinguished by their reddish colour, while unparasitized hosts remained white. The wasp's oviposition rate was determined by dividing the number parasitized by the patch time.

The parasitized hosts from each wasp were dissected from the leaf, placed on a moist filter paper disc inside a petri plate, and set aside until the wasp's offspring completed development. The behaviour of all daughters was measured using the same procedure described above.

\section{Statistical analysis}

We used a mixed-model nested ANOVA (Sokal \& Rohlf, 1981) to test whether sites (fixed effect) and isolines within sites (random effect) influenced the six quantitative traits. Because there was no change in trait means among generations (see Results, Table 1), we pooled morphological data from early (generations 2-3) and late (generations 6-8) generations. For the behavioural data we used only measures from the 10 mothers (their daughters were excluded). A separate ANOVA was performed for each trait, and the variances were partitioned among sites (HS, CC, SF), isolines within sites, and wasps within isolines. Analyses were performed in PROC GLM (SAS Institute, 1985), and type III sums of squares were used to adjust for unequal sample sizes among sites and isolines (Sokal \& Rohlf, 1981). Data for the morphological traits approximated a normal distribution (based on visual inspection of the data) and required no transformation prior to analysis. However, data for behavioural traits were skewed to the right and required a logarithmic (natural $\log$ ) transformation to obtain normality.

The variance components for each trait were estimated using PROC VARCOMP (SAS Institute, 1985). Variance among isolines $\left(\sigma_{\text {lines }}^{2}\right)$ and sites $\left(\sigma_{\text {sites }}^{2}\right)$ contributed to the total genetic variance in a trait. $\sigma_{\text {lines }}^{2}$ was attributable primarily to differences among genotypes ( $=$ foundress females), while $\sigma_{\text {sites }}^{2}$ was a consequence of both genetic (differentiation among sites resulting from natural selection or genetic drift) and environmental influences. Because $\sigma_{\text {sites }}^{2}$ contained an undetermined amount of environmental variance, we excluded it from our estimation of the trait's total genetic variance, $V_{\mathrm{G}}$. We used $\sigma_{\text {lines }}^{2}$ as an estimate of $V_{\mathrm{G}}$, which was conservative because it did not contain all the genetic variance in the trait. Our measure of $V_{\mathrm{G}}$ may have been inflated by maternal effects. However, we assumed that these effects were small because all wasps used in the analyses were reared for at least two generations under uniform laboratory conditions, and no trends over generations were found. We also reported the genetic variance as a mean-standardized statistic, $C V_{\mathrm{G}}$, where $C V_{\mathrm{G}}=100 \sqrt{ }\left(V_{\mathrm{G}} / \bar{x}\right)$. This provided a relative measure of the 'evolvability' (ability to respond to selection) of a trait, and allowed for among-trait comparisons of genetic variances (Charlesworth, 1984; Houle, 1992). Similarly, we calculated the coefficients of residual variance as $C V_{\mathrm{R}}=100 \sqrt{ }\left(V_{\mathrm{R}} / \bar{x}\right)$, where $V_{\mathrm{R}}=\sigma_{\text {error }}^{2}$ (the variance among wasps within isolines).

The phenotypic variance, $V_{\mathrm{P}}$, was calculated as the sum of the pure genetic $\left(V_{\mathrm{G}}\right)$ and pure environmental $\left(V_{\mathrm{R}}\right)$ variances, and the ratio of $V_{\mathrm{G}}$ to $V_{\mathrm{P}}$ provided an estimate of the broad-sense heritability, $h^{2}$ (Falconer, 1989). Standard errors for $h^{2}$ were computed using the formula provided by Becker (1984, p. 59). Because our data were only slightly unbalanced (sample sizes for isolines ranged from 8 to 13), estimates of standard errors of $h^{2}$ should be relatively unbiased (Searle, 1971).

Heritability of traits was also estimated from the correlation of trait values between generations. For the morphological traits, trait means from generations 2-3 (x-coordinate) were plotted against trait means from generations 5-7 ( $y$-coordinate) for each isoline. This is similar to a parent-offspring correlation, but with mothers compared to their greatgreat-granddaughters. The slope of this regression is another measure of the broad-sense heritability (Falconer, 1989). For each behavioural trait, the trait values of daughters were averaged and regressed against their mothers. Heritability was equal to the slope of the regression, as described above. Standard errors for $h^{2}$ were computed using the formula provided by Becker (1984, p. 105). We note here that the heritability estimates based on regression included potential genetic contributions from sites, as well as all nongenetic maternal effects. Consequently, heritabilities based on regression were expected to be higher than those based on ANOVA if site and/or maternal effects were substantial.

Broad-sense genetic correlations among traits 
were determined from Pearson's correlations $\left(r_{\mathrm{P}}\right)$ using isoline means (Via, 1984). This method provided an approximation to the genetic full-sib correlation because each of the terms in $r_{\mathrm{P}}$ contained not only the variance and covariance among isolines, but also a fraction of the within-isoline error variance or covariance (Via, 1984). However, with moderate sample size, the isoline mean correlation should not differ markedly from a genetic full-sib correlation. Our reason for using isoline means was that the morphological and behavioural traits were measured from different subsets of wasps per isoline (egg counts required the sacrifice of newly eclosed adult wasps with no ovipositional experience). Therefore, individual wasps could not be used to generate a correlation matrix for all six traits.

\section{Results}

Forty-one of the 63 isolines survived through at least six generations and yielded a complete set of measurements for the six traits: 20 for site HS, 11 for SF and 10 for CC. Most of the remaining 22 isolines were abandoned because there were insufficient numbers of hosts to maintain them.

Through seven laboratory generations $\left(\mathrm{F}_{2}-\mathrm{F}_{8}\right)$, no trend in the mean and variance for any of the six traits, including sex ratio, appeared (Table 1). The least squares regression of isoline means per generation (dependent variable) against generation number (independent variable) demonstrated no tendency in any trait to increase or decrease in value over time in the laboratory. The same result was observed for the regression of the traits' standard deviations among isolines per generation and generation number.

There was considerable phenotypic variability among isolines for each of the six quantitative traits (Fig. 1). Site of origin of the isolines contributed little to the variation in trait means (Tables 2 and 3 ). On the other hand, differences among isolines within sites explained a significant fraction (on average 42 per cent) of the phenotypic variability in all traits except oviposition rate (Tables 2 and 3 ). These differences are presumably genetic in origin. However, only egg number $\left(h^{2}=0.47\right)$ and ovipositor length $\left(h^{2}=0.36\right)$ had estimates of $h^{2}$ that differed significantly from zero (Table 4).

Isolines varied greatly in mean egg number from 26 to 40 eggs per wasp (Fig. 1a), a difference of 54 per cent in potential fitness between the least and most fecund isolines. On the other hand, the range of ovipositor lengths among isolines was small, accounting for only a 14 per cent difference between the extremes (Fig. 1b). Overall, there was no difference in the amount of genetic variance $\left(C V_{\mathrm{G}}\right)$ between morphological and behavioural traits (Table $4 ; t_{4}=1.75, P=0.155$ ), but the former had much lower residual variance $\left(C V_{\mathrm{R}}\right)$ than the latter $\left(t_{4}=5.37, P=0.006\right)$. This difference resulted in the significantly higher estimates of $h^{2}$ for morphological than behavioural traits $(0.34 \pm 0.08 \quad[ \pm \mathrm{SE}]$ and

Table 1 Correlations in Anagrus delicatus between isoline means per laboratory generation and generation number $\left(\mathrm{F}_{2}-\mathrm{F}_{8}\right)$ for each trait, and between phenotypic variance per generation (estimated as the standard deviation of isoline means per generation) and generation number

\begin{tabular}{lrrrrrrrr}
\hline & \multicolumn{3}{c}{$\begin{array}{c}\text { Means per } \\
\text { generation }\end{array}$} & & \multicolumn{3}{c}{$\begin{array}{c}\text { Variance per } \\
\text { generation }\end{array}$} \\
\cline { 2 - 3 } Trait & \multicolumn{1}{c}{$R^{2}$} & $P$ & $n$ & & $R^{2}$ & $P$ & $n$ \\
\hline Sex ratio $[\mathrm{F} /(\mathrm{M}+\mathrm{F})] \dagger$ & 0.24 & 0.212 & 8 & & & \\
Egg number & 0.01 & 0.553 & 89 & & -0.05 & 0.625 & 7 \\
Ovipositor length $(\mu \mathrm{m})$ & -0.07 & 0.055 & 89 & & 0.14 & 0.412 & 7 \\
Tibia length $(\mu \mathrm{m})$ & 0.02 & 0.199 & 87 & & -0.16 & 0.371 & 7 \\
Patch time $(h)$ & 0.01 & 0.406 & 55 & & 0.02 & 0.795 & 6 \\
No. parasitized & -0.01 & 0.406 & 55 & -0.33 & 0.236 & 6 \\
Oviposition rate $\left(h^{-1}\right)$ & -0.05 & 0.115 & 55 & -0.01 & 0.859 & 6 \\
\hline
\end{tabular}

$\nmid$ Because only one estimate of sex ratio per generation was available, no correlation between phenotypic variance and generation could be made. Data are based on all sites combined.

$R^{2}$, square of Pearson's correlation coefficient.

$n$, sample size. 

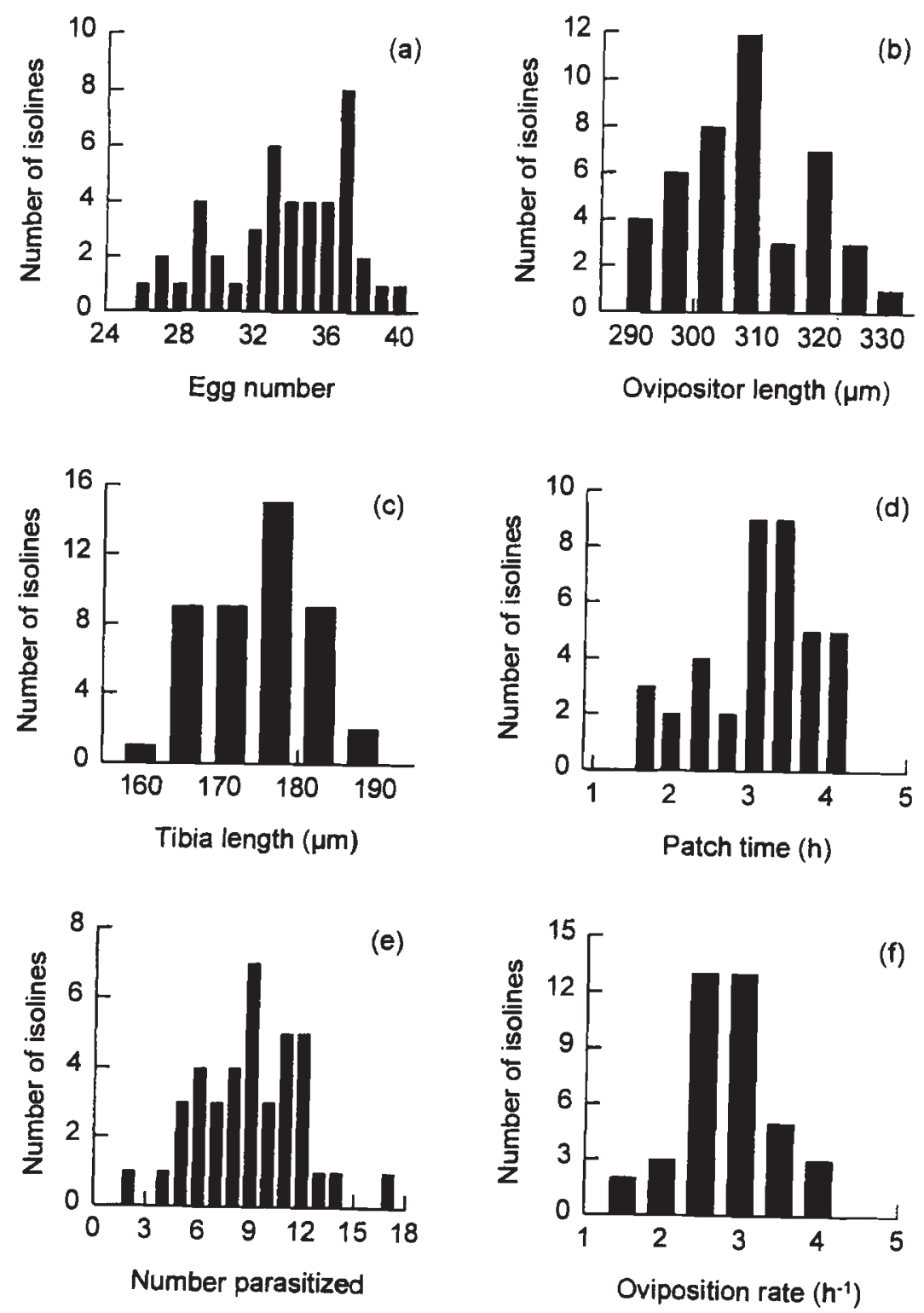

Fig. 1 The distribution of trait means for 41 isolines of Anagrus delicatus. Traits: (a) egg numbers (mean $\pm \mathrm{SE}=34.0 \pm 0.5$ ), (b) ovipositor length $(306.6 \pm 1.8 \mu \mathrm{m})$, (c) hind tibia length $(174.7 \pm 0.9 \mu \mathrm{m})$, (d) patch time $(3.1 \pm 0.1 \mathrm{~h})$, (e) number of ovipositions $(9.0 \pm 0.5)$, (f) oviposition rate $\left(2.8 \pm 0.1 \mathrm{~h}^{-1}\right)$.

$0.08 \pm 0.02$, respectively; $t_{4}=3.24, P=0.032$ ).

The correlation of trait means between early $\left(\mathrm{F}_{2}-\right.$ $\left.F_{3}\right)$ and late $\left(F_{5}-F_{7}\right)$ generations for 41 isolines was significantly positive for egg number and ovipositor length (Fig. 2a,b), but not for tibia length (Fig. 2c). Parent-offspring regressions for the three behavioural traits were not significant (Fig. 3). Estimates of the repeatability between generations were comparable to those based on ANOVA (Table 4): both methods showed that only egg number and ovipositor length had 95 per cent confidence intervals around $h^{2}$ that did not overlap zero. However, for egg number, $h^{2}$ was significantly higher when estimated from the regression between generations than when estimated from ANOVA.
Many of the traits examined were genetically correlated (Table 5). All morphological traits were positively correlated: isolines of larger female wasps were more fecund and had longer ovipositors. The behavioural traits patch time, number of hosts parasitized and oviposition rate were also positively correlated. In addition, there were also positive genetic correlations between oviposition rate and the morphological traits egg number and tibia length.

\section{Discussion}

In a previous study (Cronin \& Strong, 1993a), we proposed that the foraging behaviour of $A$. delicatus 
Table 2 Morphological traits of Anagrus delicatus: results of ANOva for the effects of site (HS, SF, CC) and wasp isoline on egg number, ovipositor length and mean tibia length

\begin{tabular}{lrrrr}
\hline Trait & d.f. & MS & $F$ & \multicolumn{1}{c}{$P$} \\
\hline Egg number & & & & \\
$\quad$ Site & 2 & 195.86 & 2.06 & 0.142 \\
$\quad$ Isolines w/in sites & 38 & 95.31 & 8.65 & $<0.001$ \\
$\quad$ Wasps w/in lines & 318 & 11.02 & & \\
Ovipositor length & & & & \\
$\quad$ Sites & 2 & 49.62 & 2.29 & 0.115 \\
$\quad$ Isolines w/in sites & 38 & 21.68 & 3.15 & $<0.001$ \\
$\quad$ Wasps w/in lines & 316 & 6.89 & & \\
Tibia length & 2 & & & \\
$\quad$ Site & 38 & 8.16 & 0.51 & 0.605 \\
$\quad$ Isolines w/in sites & 307 & 2.17 & 3.13 & $<0.001$ \\
$\quad$ Wasps w/in lines & & & \\
\hline
\end{tabular}

$F$ statistic for the site main effect is the ratio MS Sites/MS Isolines, and the $F$ statistic for isolines within sites is the ratio MS Isolines/MS Wasps.

Table 3 Behavioural traits of Anagrus delicatus: results of ANOva for the effects of site (HS, SF, CC) and wasp isoline on patch time, number parasitized per patch and oviposition rate per patch

\begin{tabular}{lrrrr}
\hline Trait & d.f. & MS & $F$ & \multicolumn{1}{c}{$P$} \\
\hline Patch time & 2 & 0.80 & 1.37 & 0.271 \\
$\quad$ Site & 30 & 0.59 & 2.32 & $<0.001$ \\
$\quad$ Isolines w/in sites & 310 & 0.25 & & \\
$\quad$ Wasps w/in lines & & & & \\
Number parasitized & 2 & 0.75 & 0.42 & 0.664 \\
$\quad$ Sites & 30 & 1.80 & 2.05 & $<0.001$ \\
$\quad$ Isolines w/in sites & 308 & 0.88 & & \\
$\quad$ Wasps w/in lines & 2 & 0.20 & 0.56 & 0.576 \\
Oviposition rate & 30 & 0.35 & 1.09 & 0.352 \\
$\quad$ Site & 302 & 0.33 & & \\
$\quad$ Isolines w/in sites & & &
\end{tabular}

Data were natural log transformed prior to analysis.

$F$ statistic determined as in Table 2 .

reflects a risk-spreading strategy. Traits most important to the evolution of this strategy (or other hypothesized strategies; see Introduction) include the behavioural response of wasps to individual host patches; in particular, time spent and number of hosts parasitized per patch. Here, we have found evidence for significant genetic variance in these traits, and in several morphological traits (egg number, ovipositor length and body size) associated with the oviposition success and fitness of $A$. delicatus. Despite similar levels of genetic variance, the behavioural traits had higher residual variances than the morphological traits, and consequently lower heritabilities. Although the absolute response to selection, $R$, is predicted to be higher for the morphological traits (because of the familiar relationship $R=h^{2} S$, where $S$ is the selection differential; Falconer, 1989), similar mean-standardized genetic variances would suggest that the relative responses to selection ('evolvability') of the behavioural traits are comparable to the morphological traits (Houle, 1992).

We conclude that there is considerable potential for the evolution of these behavioural and morphological traits, and that selection experiments could be devised to alter the unusual behavioural strategy 
Table 4 Broad-sense heritability estimates $\left(h^{2} \pm \mathrm{SE}\right)$ and coefficients of genetic $\left(C V_{G}\right)$ and residual $\left(C V_{R}\right)$ variance for six traits in Anagrus delicatus

\begin{tabular}{lccrr}
\hline Trait & $\begin{array}{c}\text { Variation among } \\
\text { isolines (ANOVA) } \\
\left(h^{2}\right)\end{array}$ & $\begin{array}{c}\text { Intergeneration } \\
\text { regression } \\
\left(h^{2}\right)\end{array}$ & $C V_{\mathrm{G}}$ & $C V_{\mathrm{R}}$ \\
\hline Egg number & $0.47 \pm 0.16^{*}$ & $0.71 \pm 0.09^{*}$ & 8.81 & 9.76 \\
Ovipositor length & $0.36 \pm 0.17^{*}$ & $0.54 \pm 0.18^{*}$ & 2.59 & 4.89 \\
Tibia length & $0.20 \pm 0.22$ & $0.28 \pm 0.23$ & 2.58 & 5.27 \\
Patch time & $0.11 \pm 0.16$ & $0.09 \pm 0.09$ & 14.07 & 46.24 \\
No. parasitized & $0.09 \pm 0.16$ & $0.11 \pm 0.10$ & 18.92 & 73.22 \\
Oviposition rate & $0.05 \pm 0.14$ & $0.03 \pm 0.11$ & 5.02 & 84.27 \\
\hline
\end{tabular}

Estimates were determined from an ANOVA on isoline means and from regressions between generations.

${ }^{*} P<0.05$.

of $A$. delicatus (e.g. select for wasp isolines that lay more eggs per host patch and consequently visit fewer patches). Our goal is to use these data as a framework for the development of a quantitativegenetic model that explores the evolution and selective advantage of this strategy, and to test predictions from this model in experimental, mixed-isoline, populations of $A$. delicatus.

Many of the traits associated with $A$. delicatus oviposition success are genetically correlated. Positive correlations among the morphological traits were to be expected because of their probable allometric relationship to body size. Also expected were the correlations among the behavioural traits; this was because patch time, number of ovipositions and oviposition rate were integrally dependent upon each other. We have no rationalization for the correlations between oviposition rate and the two morphometric traits, tibia length and egg number. Although the cause was unknown, this relationship leads to the prediction that larger wasps will have greater fecundity and lay eggs at a higher rate. Wasps with this combination of attributes are likely to be more efficient natural enemies, suggesting that artificial selection could improve the utility of this parasitoid for the biological control of its host.

Anagrus delicatus are pro-ovigenic, with a fixed egg load that is mature at eclosion (Cronin \& Strong, 1993a). An examination of adult wasps captured in the field in Florida revealed that at least 7 per cent of the females had laid all of their eggs (no eggs remained in the ovarioles) (Cronin, 1991). This suggested egg-limitation for at least a fraction of the population. By this reasoning, higher fitness may be achieved by wasps with more eggs: i.e. egg load may be a good proxy for fitness, especially for short-lived pro-ovigenic species like $A$. delicatus. Traits that are closely connected to fitness (e.g. life-history traits) are often inferred to have been purged of genetic variance by selection, and hence have lower heritabilities (Gustafsson, 1986; Charlesworth, 1987; Mousseau \& Roff, 1987; Roff \& Mousseau, 1987). Thus, the relatively high genetic variance and heritability of egg load $\left(h^{2} \approx 0.47-0.71\right)$ may be considered unexpected. For an alternate viewpoint, see Price \& Schluter (1991) and Houle (1992).

Unlike egg number, ovipositor length has no obvious effect on $A$. delicatus foraging success or fitness. Although for some parasitoid species ovipositor length determines the accessibility of hosts (e.g. Ball \& Dalhsten, 1973; Weis et al., 1985), such a relationship does not hold for $A$. delicatus. Prokelisia hosts are located just beneath the surface of a cord grass leaf and are easily reached and parasitized by wasps of all ovipositor lengths (Cronin \& Strong, 1993a). On the other hand, ovipositor length is correlated with egg number. There may also be developmental or maintenance costs involved in having long ovipositors that cause reduced fitness in comparison to wasps with shorter ovipositors; but that remains to be determined.

No significant divergence (genetic or otherwise) in wasp morphology or behaviour among sites was detected, even though sites in the San Francisco Bay were separated by a distance of $8-24 \mathrm{~km}$. This result is not unexpected considering the remarkable dispersal capabilities of $A$. delicatus. These small wasps have regularly been captured several kilometres or more away from their host habitat (Antolin \& Strong, 1987; J. T. Cronin \& D. R. Strong, unpublished data). Thus, it is likely that the three sites are linked by migration and that they have evolved as a 


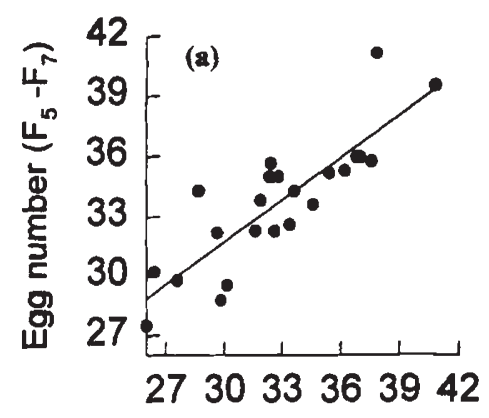

Egg number $\left(F_{2}-F_{3}\right)$
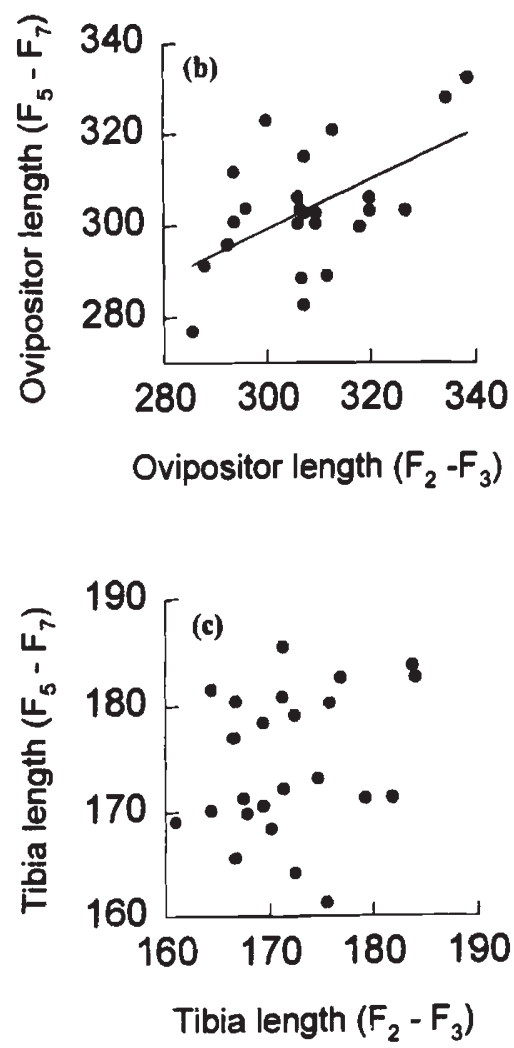

Fig. 2 Correlation of trait means between early $\left(\mathrm{F}_{2}-\mathrm{F}_{3}\right)$ and late $\left(F_{5}-F_{7}\right)$ generations for 41 isolines of Anagrus delicatus. Traits: (a) egg numbers $(y=0.71 x+10.31$, $r^{2}=0.73, P<0.001$ ), (b) ovipositor length $\left(y=0.54 x+136.05, r^{2}=0.30, P=0.006\right)$, (c) hind tibia length $\left(y=0.28 x+127.60, r^{2}=0.06, P=0.239\right)$. Lines are fit by least squares regression.

single population.

Substantial genetic variability among just 41 isolines of $A$. delicatus suggests that the diversity of 'clones' in the San Francisco Bay is relatively high. The spatial fragmentation and patchiness associated with the distribution of Spartina spp. (at least up to $24 \mathrm{~km}$ ) does not appear to contribute significantly to overall clonal diversity (as discussed above). Based

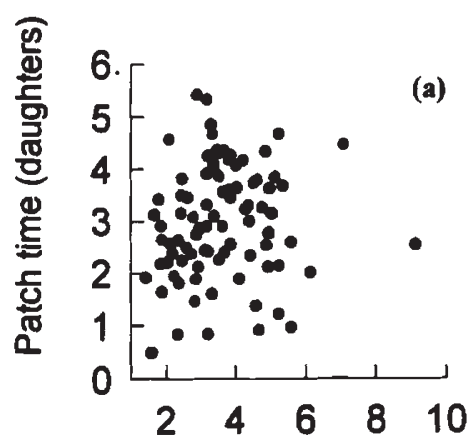

Patch time (mother)

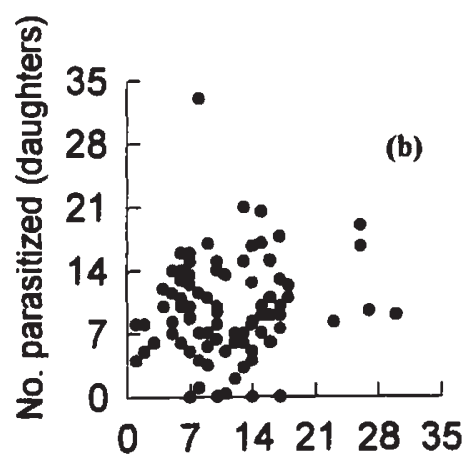

No. parasitized (mother)

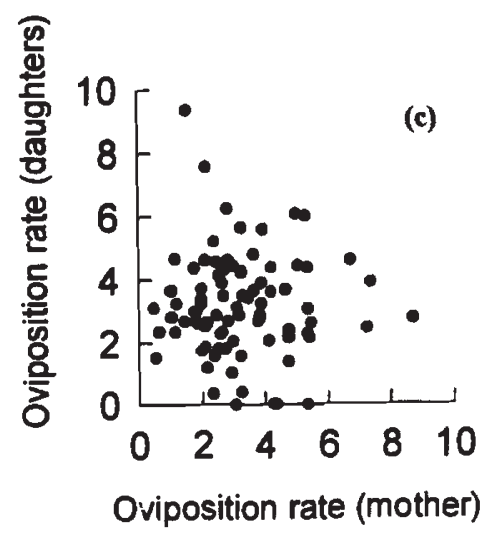

Fig. 3 Parent-offspring regressions for the behavioural traits (a) patch time $\left(y=0.09 x+2.70, r^{2}=0.01, P=0.343\right)$, (b) number of ovipositions $\left(y=0.11 x+8.51, r^{2}=0.02\right.$, $P=0.282)$ and (c) oviposition rate $(y=-0.03 x+3.27$, $r^{2}=0.001, P=0.807$ ) of Anagrus delicatus.

on our laboratory experiments and field observations, there is no resource partitioning or niche distinctions that would lead to an adaptive explanation of the different clones. The ecological similarity among $A$. delicatus clones should lead to broadly overlapping niches and intense competition, and thus to reduced diversity (Roughgarden, 1972; Williams, 1975). Possible explanations for the maintenance of clonal diversity are that the parth- 
Table 5 Correlation among morphological and behavioural traits based on mean trait values for 41 isolines (all sites combined)

\begin{tabular}{lccccc}
\hline & $\begin{array}{c}\text { Egg } \\
\text { number }\end{array}$ & $\begin{array}{c}\text { Ovipositor } \\
\text { length }\end{array}$ & $\begin{array}{c}\text { Tibia } \\
\text { length }\end{array}$ & $\begin{array}{c}\text { Patch } \\
\text { time }\end{array}$ & $\begin{array}{c}\text { No. } \\
\text { parasitized }\end{array}$ \\
\hline Egg number & 1.00 & & & & \\
Ovipositor length & $0.41^{* *}$ & 1.00 & & & \\
Tibia length & $0.65^{* * *}$ & $0.61^{* * *}$ & 1.00 & & \\
Patch time & -0.10 & -0.01 & -0.28 & 1.00 & \\
No. parasitized & 0.13 & 0.06 & -0.01 & $0.83^{* * * *}$ & 1.00 \\
Oviposition rate & $0.34^{*}$ & 0.23 & $0.38^{*}$ & $0.32^{*}$ & $0.77^{* * * *}$ \\
\hline
\end{tabular}

Correlations were calculated using Pearson's $r_{P}$ (Sokal \& Rohlf, 1981).

${ }^{*} P<0.05,{ }^{*} P<<0.01,{ }^{*} * * P<0.001$.

enogenetic populations of $A$. delicatus are polyphyletic, or that they are recently derived from sexual populations (e.g. Harshman \& Futuyma, 1985; Crease et al., 1989; Wilson \& Hebert, 1992). We presently have no information regarding the origin or phylogeny of San Francisco Bay A. delicatus.

\section{Acknowledgements}

This project could not have been completed without the assistance of K. Arico. M. Antolin, D. Carr, B. Schaeffer, M. Strand and M. Turelli provided invaluable suggestions for the improvement of this manuscript. Funding was provided by NSF grant DEB91-96207 to D. R. Strong.

\section{References}

ANTOLIN, M. F. AND STRONG, D. R. 1987. Long-distance dispersal by a parasitoid (Anagrus delicatus, Mymaridae) and its host. Oecologia, 73, 288-292.

BALL, J. C. AND DAHLSTEN, D. L. 1973. Hymenopterous parasites of Ips paraconfusus (Coleoptera: Scolytidae) larvae and their contribution to mortality. I. Influence of host tree and tree diameter on parasitization. Can. Ent., 105, 1453-1464.

BECKER, w. A. 1984. Manual of Quantitative Genetics, 4th edn. Academic Enterprises, Pullman, WA.

Bouletreau, M 1986. The genetic and coevolutionary interactions between parasitoids and their hosts. In: Waage, J. K. and Greathead, D. J. (eds) Insect Parasitoids, pp. 169-200. Academic Press, New York.

BOUSKILA, A., ROBERTSON, I. C., ROBINSON, M. E., ROITBERG, B. D., TENHUMBERG, B., TYRE, A. J., VANRANDEN, E. 1995. Submaximal oviposition rates in a mymarid parasitoid: choosiness should not be ignored. Ecology, 76, 1990-1993.

CARTON, Y., CAPY, P. AND NAPPI, A. J 1989. Genetic variability of host-parasite relationship traits: utilization of isofemale lines in a Drosophila simulans parasitic wasp. Génét. Sél. Évol., 21, 437-446.

CARTON Y. AND NAPPI, A. 1991. The Drosophila immune reaction and the parasitoid capacity to evade it: genetic and coevolutionary aspects. Acta Oecologica, 12, 89-104.

CHARLESWORTH, B. 1984. The evolutionary genetics of life histories. In: Shorrocks, B. (ed) Evolutionary Ecology, pp. 117-133. Blackwell Scientific Publications, Oxford.

CHARLESWORTH, B. 1987. The heritability of fitness. In: J. Bradbury and Andersson, M. (eds) Sexual Selection: Testing the Alternatives, pp. 21-40 Wiley, New York.

CHARLESWORTH, D. AND CHARLESWORTH, B. 1987. Inbreeding depression and its evolutionary consequences. Ann. Rev. Ecol. Syst., 18, 237-268.

CHARNOV, E. L. AND SKINNER, S. w. 1988. Clutch size in parasitoids: the egg production rate as a constraint. Evol. Ecol., 2, 167-174.

CHASSAIN, C AND BOUlETREAU, M. 1987. Genetic variability in the egg-laying behavior of Trichogramma maidis. Entomophaga, 32, 149-157.

Chassain, C. AND Bouletreau, M. 1991. Genetic variability in quantitative traits of host exploitation in Trichogramma (Hymenoptera: Trichogrammatidae). Genetica, 83, 195-202.

CREASE, T. J., STANTON, D. J. AND HEBERT, P. D. N. 1989. Polyphyletic origins of asexuality in Daphnia pulex. II. Mitochondrial-DNA variation. Evolution, 43, 1016-1026.

CRONIN, J. T. 1991. Parasitoid Foraging Behavior and the Stabilization of Host-Parasitoid Populations. Ph.D. Thesis, Florida State University, Tallahassee, FL.

CRONin, J. T. AND STRONG, D. R. 1990. Biology of Anagrus delicatus (Hymenoptera: Mymaridae), an egg parasitoid of Prokelisia marginata (Homoptera: Delphacidae). Ann. Entomol. Soc. Am., 83, 846-854.

CRONIN, J. T. AND STRONG, D. R. 1993a. Substantially submaximal oviposition rates by a mymarid egg parasitoid in the laboratory and field. Ecology, 74, 1813-1825.

CRONIN, J. T. AND STRONG, D. R. 1993b. Superparasitism and mutual interference in the egg parasitoid Anagrus 
delicatus (Hymenoptera: Mymaridae). Ecol. Entomol., 18, 293-302.

DENNO, R. F., SCHAUFF, M. E., WILSON, S. W. AND OLMSTEAD, K. L. 1987. Practical diagnosis and natural history of two sibling salt marsh-inhabiting planthoppers (Homoptera: Delphacidae). Proc. Entomol. Soc. Wash., 89, 687-700.

FALCONER, D. S. 1989. Introduction to Quantitative Genetics, 3rd edn. Longman, New York.

GODFRAY, H. C. J. 1987. Clutch size evolution in parasitic wasps. Am. Nat., 129, 221-233.

GODFRAY, H. C. J. 1993. Parasitoids: Behavioral and Evolutionary Ecology. Princeton University Press, Princeton, NJ.

GODFRAY, H. C. J. AND IVES, A. R. 1988. Stochasticity in invertebrate clutch-size models. Theor. Pop. Biol., 33, $79-101$.

GUSTAFSSON, L. 1986. Lifetime reproductive success and heritability: empirical support for Fisher's fundamental theorem. Am. Nat., 128, 761-764.

HAMiLton, w. D. 1967. Extraordinary sex ratios. Science, 156, 477-488.

HARSHMAN, L. G. AND FUTUYMA, D. J. 1985. The origin and distribution of clonal diversity in Alsophila pometaria (Lepidoptera: Geometridae). Evolution, 39, 315-324.

HOULE, D. 1992. Comparing evolvability and variability of quantitative traits. Genetics, 130, 195-204.

MANGEL, M. 1992. Descriptions of superparasitism by optimal foraging theory, evolutionarily stable strategies and quantitative genetics. Evol. Ecol., 6, 152-169.

MANGEL, M. AND Clark, C. w. 1988. Dynamic Modeling in Behavioral Ecology. Princeton University Press, Princeton, NJ.

MOLLEMA, c. 1991. Heritability estimates of host selection behavior by the Drosophila parasitoid Asobara tabida. Neth. J. Zool., 41, 174-183.

MOUSSEAU, T. A. AND ROFF, D. A. 1987. Natural selection and the heritability of fitness components. Heredity, 59, 181-197.

NUNNEY, L. AND LUCK, R. F. 1988. Factors influencing the optimum sex ratio in a structured population. Theor. Pop. Biol., 33, 1-30.

ORZACK, S. H. AND GLADSTONE, J. 1994. Quantitative genetics of sex ratio traits in the parasitic wasp, Nasonia vitripennis. Genetics, 137, 211-220.

ORZACK, S. H. AND PARKER, D. E., JR. 1990. Genetic variation for sex ratio traits within natural populations of a parasitic wasp, Nasonia vitripennis. Genetics, 124, 373-384.

PARKER, G. A. AND COURTNEY, S. P. 1984. Models of clutch size in insect oviposition. Theor. Pop. Biol., 26, 27-48.

PREVOST, G. AND LEWIS, w. J. 1990. Heritable differences in the response of the braconid wasp Micropletis croceipes to volatile allelochemicals. J. Insect Behav., 3, 277-287.

PRICE, T. AND SCHLUTER, D. 1991. On the low heritability of life-history traits. Evolution, 45, 853-861.

RODERICK, G. K. 1987. Ecology and Evolution of Dispersal in Californian Populations of a Salt Marsh Insect, Prokelisia marginata. Ph.D. Thesis, University of California,
Berkeley.

ROFF, D. A. AND MOUSSEAU, T. A. 1987. Quantitative genetics and fitness: lessons from Drosophila. Heredity, 58, 103-118.

Rosenheim, J. A. AND MANGel, M. 1994. Patch leaving rules for parasitoids with imperfect host discrimination. Ecol. Entomol., 19, 374-380.

ROUGHGarden, J. 1972. The evolution of niche width. Amer. Natur., 106, 683-718.

SAS institute 1985. SAS Users Guide: Statistics, Version 5. SAS Institute, Cary, NC.

SEARLE, S. R. 1971. Linear Models. Wiley, New York.

SEQUEIRA, R. AND MACKAUER, M. 1992a. Quantitative genetics of body size and development time in the parasitoid wasp Aphidus ervi (Hymenoptera: Aphididae). Can. J. Zool., 70, 1102-1108.

SEQUEIRA, R. AND MACKAUER, M. 1992b. Covariance of adult size and development time in the parasitoid wasp Aphidus ervi in relation to the size of its host, Acyrthosiphon pisum. Evol. Ecol., 6, 34-44.

SOKAL, R. R. AND ROHLF, F. J. 1981. Biometry, 2nd edn. Freeman, New York.

SPICHER, D. AND JOSSELYN, M. 1985. Spartina (Gramineae) in northern California: distribution and taxonomic notes. Madroño, 32, 158-167.

STEPHENS, D. W. AND KREBS, J. R. 186. Foraging Theory. Princeton University Press, Princeton, NJ.

STILING, P. D. AND STRONG, D. R. 1982. Egg density and the intensity of parasitism in Prokelisia marginata (Homoptera: Delphacidae). Ecology, 63, 1630-1635.

STOUTHAMER, R. AND LUCK, R. F. 1993 . Influence of microbe-associated parthenogenesis on the fecundity of Trichogramma deion and T. pretiosum. Entomologia exp. appl., 67, 183-192.

STOUTHHAMER, R. AND WERREN, J. H. 1993. Microbes associated with parthenogenesis in wasps of the genus Trichogramma. J. Invert. Path., 61, 6-9.

STRONG, D. R. 1988. Parasitoid theory: from aggregation to dispersal. Trends Ecol. Evol., 3, 277-280.

STRONG, D. R. 1989. Density independence in space and inconsistent temporal relationships for host mortality caused by a fairyfly parasitoid. J. Anim. Ecol., 57, 1065-1076.

TAYLOR, P. D. AND BULMER, M. G. 1980. Local mate competition and the sex ratio. J. Theor. Biol., 86, 409-419.

VIA, s. 1984. The quantitative genetics of polyphagy in an insect herbivore. II. Genetic correlations in larval performance within and among host plants. Evolution, 38, 896-905.

VISSER, M. E., VAN ALPHEN, J. J. M. AND HEMERIK, L. 1992. Adaptive superparasitism and patch time allocation in solitary parasitoids: an ESS model. J. Anim. Ecol., 61, 93-101.

WAJNBERG, E. 1993. Genetic variation in sex allocation in a parasitic wasp: variation in sex pattern within sequences of oviposition. Entomologia exp. appl., 69, 221-229.

WAJNBERG, E., PIZZOL, J. AND BABAULT, M. 1989. Genetic variation in progeny allocation in Trichogramma maidis. Entomologia exp. appl., 53, 177-187. 
WEIS, A. E., ABRAHAMSON, W. G. AND MCCREA, K. D. 1985. Host gall size and oviposition success by the parasitoid Eurytoma gigantea. Ecol. Entomol., 10, 341-348.

WERREN, J. H., SKINNER, S. W. AND HUGER, A. M. 1986. Male-killing bacteria in a parasitic wasp. Science, 231, 990-992.
Williams, G. c. 1975. Sex and Evolution. Princeton University Press, Princeton, NJ.

WILSON, C. C. AND HEBERT, P. D. N. 1992. The maintenance of taxon diversity in an asexual assemblage: an experimental analysis. Ecology, 73, 1462-1472. 